\title{
Persistent spontaneous synovial drainage from digital flexor sheath in proliferative tenosynovitis: Two case reports and a review of the literature
}

\author{
Brian Chin BHSc MD(c) ${ }^{1}$, Kevin Cheung MSc MD ${ }^{2 *}$, Hana Farhangkhoee MSc MD ${ }^{2 *}$, \\ Achilleas Thoma MD MSc FRCSC FACS ${ }^{2,3}$
}

\begin{abstract}
B Chin, K Cheung, H Farhangkhoee, A Thoma. Persistent spontaneous synovial drainage from digital flexor sheath in proliferative tenosynovitis: Two case reports and a review of the literature. Plast Surg
\end{abstract} 2015;23(2):108-110.

\begin{abstract}
Un épanchement de synovie persistant et spontané de la gaine des fléchisseurs d'un doigt en présence d'une ténosynovite proliférative : deux rapports de cas et une analyse bibliographique
\end{abstract}

Proliferative flexor tenosynovitis of the hand is an inflammatory process involving the synovial sheaths surrounding the tendons. It is most commonly caused by infection, but may also be caused by overuse, diabetes and rheumatic conditions such as rheumatoid arthritis and crystal arthropathies. The present report describes two patients with severe proliferative tenosynovitis, who developed a fistula between the tendon sheath and skin after instrumentation, resulting in persistent synovial drainage. After failing conservative management, both patients were managed with extensive flexor tenosynovectomy to prevent inoculation of bacteria into the flexor sheath. The presentation, management and outcome of each case is described in addition to a discussion of the literature on tenosynovial fistulas.

Key Words: Fistula; Flexor tendon; Synovial; Tenosynovitis
La ténosynovite proliférative des fléchisseurs de la main est un processus inflammatoire qui touche les gaines synoviales des tendons. Généralement causée par une infection, elle peut également être attribuable à une surutilisation, au diabète et à des problèmes rhumatismaux comme la polyarthrite rhumatoïde et les arthropathies causées par des dépôts de cristaux. Le présent rapport décrit le cas de deux patients atteints d'une ténosynovite proliférative grave, qui ont développé une fistule entre la gaine du tendon et la peau après l'instrumentation, ce qui a entraîné un épanchement de synovie persistant. Après l'échec d'une prise en charge prudente, les deux patients ont été soumis à une ténosynovectomie extensive des fléchisseurs afin de prévenir l'inoculation de bactéries dans la gaine des fléchisseurs. Les auteurs exposent la présentation, la prise en charge et le résultat de chaque cas et traitent des publications sur les fistules ténosynoviales.
Flexor tenosynovitis represents a broad category of conditions involving inflammation of the flexor tendons and their synovial sheaths. Most acute cases of flexor tenosynovitis result from inoculation of bacteria and subsequent infection of the flexor tendon sheath (1), but may also be caused by noninfectious etiologies including chronic irritation from overuse (2), diabetes (3) and rheumatic diseases such as rheumatoid arthritis (4) and crystalline arthropathies (5). A distinguishing feature of tenosynovitis due to an underlying inflammatory condition is the marked proliferation of tenosynovium from chronic synovial inflammation and hyperplasia (6). The documented sequelae of proliferative tenosynovitis include swelling, increased bulk of synovial tissue, restriction of tendon motion, spontaneous tendon rupture and median nerve compression $(6,7)$. Persistent synovial drainage through a patent communication between the flexor sheath and the skin has not been previously described in patients with severe proliferative tenosynovitis. There are two documented series reporting flexor tenosynovial fistula formation of the hand after injury or trigger finger release $(8,9)$.

The present article describes two patients with proliferative tenosynovitis who developed persistent spontaneous synovial drainage following needle aspiration of what was believed to be an impending rupture of an abscess of the affected digit. Relevant features of the clinical presentation, physical examination, investigations and management are described, followed by a discussion of the literature on tenosynovial fistulas.

\section{METHODS}

The patients' history and investigations were collected through a retrospective review of St Joseph's Hospital (Hamilton, Ontario) electronic medical records. The patients granted consent for photographic documentation and publication of the present article.

\section{CASE PRESENTATIONS}

Case 1

An 86-year-old right-hand-dominant retired nurse presented with acute swelling of her right index finger. She had a history of rheumatoid arthritis treated with prednisone, methotrexate and plaquenil. The swelling was isolated to the volar terminal phalanx of the right index finger, with minimal erythema and tenderness. Full range of motion was preserved. The patient denied any recent or previous history of trauma to the digit. Needle aspiration of the pulp of the right index finger by an orthopedic surgeon yielded some clear viscous fluid. A subsequent mid-radial incision of the pulp under digital block expressed a moderate amount of the same synovial-like fluid with proximal-to-distal compression of the flexor tendon sheath. The wound was closed primarily. Although clinical suspicion of active infectious tenosynovitis was low, the patient was started on prophylactic oral antibiotics. The collected fluid samples were negative for Gram stain and culture of microorganisms. Three weeks later, the patient returned clinically unchanged with a 'bulla-like' swelling at the terminal phalanx on the volar and radial aspect. Another incision and drainage was performed with the same mid-radial approach to the pulp and primary closure.

After two attempts at drainage and a course of oral antibiotics, the swelling of the right index finger persisted and developed recurrent spontaneous drainage of synovial fluid through the radial wound of the terminal phalanx. Proximal to distal compression of the palm and along the length of the index finger would express synovial fluid through the sinus. Subsequent investigations of the synovial fluid continued to test negative for growth of aerobic and anaerobic microorganisms, as well as fungal mycology. Fluid analysis was of limited value because the total nucleated cell count was not reported. However, fluid analysis did detect

*Authors who contributed equally

${ }^{1}$ Michael G DeGroote School of Medicine; ${ }^{2}$ Division of Plastic Surgery, Department of Surgery, Faculty of Medicine; ${ }^{3}$ Department of Clinical Epidemiology and Biostatistics, McMaster University, Hamilton, Ontario

Correspondence: Dr Achilleas Thoma, 206 James Street South, Suite 101, Hamilton, Ontario L8P 3A9.

Telephone 905-523-0019, fax 905-523-0229, e-mail athoma@mcmaster.ca 


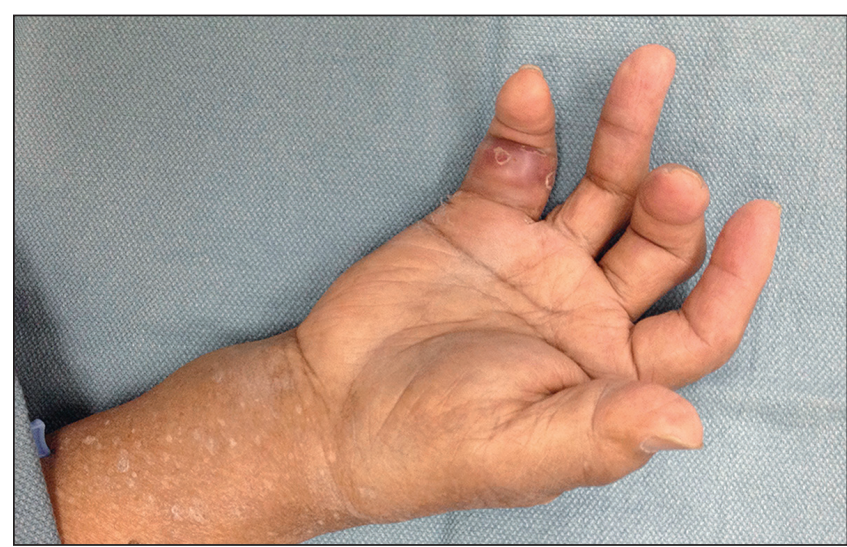

Figure 1) Case 2. Volar proximal phalanx of the right little finger with spontaneous synovial drainage

the presence of calcium pyrophosphate crystals, although $\mathrm{x}$-rays of the hand showed no bony involvement. In contrast, ultrasound of the right hand reported significant tenosynovitis of the second flexor tendon and proliferative flexor tenosynovium of the wrist. An additional attempt at conservative management, with an increase in the dose of methotrexate by the rheumatology service, yielded no improvement.

Given the risk of infectious tenosynovitis tracking through the cutaneous communication to the flexor tendon sheath, the patient consented to extensive flexor tenosynovectomy. A zigzag incision was made from the proximal phalanx of the right index finger and extending to the palm, the carpal tunnel and the distal forearm. It revealed extensive proliferative tenosynovium of the flexor tendons in the carpal tunnel and proximally to the level of the musculotendinous junction in the distal forearm. The proliferative tenosynovial tissue in the distal forearm, carpal tunnel and flexor tendon of the index finger was excised. A release of the index A1 pulley was also performed. Additionally, a prominent osteophyte was identified at the floor of the carpal tunnel. This was excised to prevent attritional rupture of the flexor tendons. Postoperatively, there was resolution of the intermittent synovial drainage through the index finger. At two months follow-up, the patient experienced no further drainage through the skin, with full range of motion of the fingers.

\section{Case 2}

A 69-year-old right-hand-dominant retired chemist presented with progressive swelling of the volar proximal phalanx of the right small finger over a one-week period. His medical history was significant for seronegative arthropathy not yet diagnosed, gout and end-stage renal disease. The patient had undergone two renal transplants, the most recent in 1997, which began to fail over the past year, requiring reinstitution of hemodialysis. He had received systemic immunosuppression with mycophenolic acid and prednisone, but following failure of the renal allograft was tapered down to prednisone alone. On further clinical history, the patient denied any incidence of trauma, infection or similar previous episodes involving the affected digit. $\mathrm{He}$ had been taking oral antibiotics for a presumed soft tissue infection. Physical examination was notable for localized swelling of the volar proximal phalanx of the right small finger (Figure 1), with minimal tenderness on palpation of the flexor sheath and joints. There was no pain with passive extension of the right small finger. Given these findings, there was low clinical suspicion for suppurative flexor tenosynovitis, septic arthritis or a gouty process. Ultrasound of the hand revealed extensive tenosynovitis of the right fifth flexor tendon and marked tenosynovitis of the remaining flexor tendons with synovial proliferation in the mid-palm and wrist. The patient's urate level was within normal limits $(315 \mu \mathrm{mol} / \mathrm{L}$ [reference range $210 \mu \mathrm{mol} / \mathrm{L}$ to $450 \mu \mathrm{mol} / \mathrm{L}$ ]), and he had a white blood cell count of $4.3 \times 10^{9} / \mathrm{L}$ and an elevated creatinine level of $417 \mu \mathrm{mol} / \mathrm{L}$ before dialysis. An attempt to aspirate the swelling using an 18-gauge needle yielded approximately $4 \mathrm{~mL}$ of viscous, straw-coloured fluid consistent with synovial fluid. There was no frank purulence present in the aspirated sample and fluid cultures were negative for growth.

Despite conservative management with oral antibiotics, the proximal phalangeal swelling did not resolve. Of greater concern, the patient developed persistent spontaneous drainage of synovial fluid through the site of aspiration. A local incision and drainage was considered but a more definitive approach under ideal sterile technique was preferred given the patient's immunosuppressed status. The patient underwent flexor tenosynovectomy through a zigzag incision from the distal phalanx of the little finger to the palm and extending past the carpal tunnel revealing proliferative tenosynovium surrounding the flexor tendons (Figure 2A). The proximal phalanx of the little finger revealed proliferative tenosynovium, which was excised around the flexor tendon. Flexor tendons in the carpal tunnel and proximal to the wrist crease were also found matted with proliferative tenosynovium (Figure 2B). Excision of tenosynovium in the distal forearm revealed that both the superficialis and profundus tendons of the ring finger had ruptured (Figure 2C). The ruptured profundus tendon of the ring finger was repaired with a side-to-side transfer to the profundus tendon of the long finger. The synovial fluid collected from the flexor sheath of the little finger was negative for urate crystals and microorganisms.

Postoperatively, there was resolution of the proximal phalangeal swelling and spontaneous synovial drainage of the little finger. However, despite the transfer repair of the profundus tendon of the ring finger, the patient was unable to flex the proximal interphalangeal joint or the distal interphalangeal joint. Given the complexity of possible flexor tendon reconstruction and the patient's medical comorbidities of end-stage renal disease and immunosuppression, it was decided to not proceed with further surgery. The patient reported being satisfied with the decision and the outcome.

\section{DISCUSSION}

The major sequelae of proliferative tenosynovitis include restriction of tendon movement, potential rupture of tendons and nerve compression contributing to impairment of hand function. Formation of a persistent communicating sinus between the tendon sheath and skin following needle aspiration in patients with proliferative tenosynovitis has not been previously described. Based on a review of the literature, we suggest that these cases represent the formation of a cutaneous tenosynovial fistula.

Synovial fistulas are known and uncommon postoperative complication following arthroscopy of the knee $(10,11)$. There are also documented cases of synovial fistulas developing after ankle arthroscopy (12), open rotator cuff repair (13) and wrist arthroscopy (14). Flexor tenosynovial fistulas of the hand are uncommon, which is reflected by the paucity of literature. There is one documented case of a tenosynovial fistula as a complication of open trigger finger release that failed conservative management with oral antibiotics and required surgical excision (8). A retrospective case series by Naam (9) reported 15 patients presenting with tenosynovial fistulas after an injury or multiple release of recurrent stenosing flexor tenosynovitis with intraoperative steroid injections. While it is clear that the nature of instrumentation or surgical intervention creates an iatrogenic communication between the inner and external environment, these channels are temporary and obliterate with proper wound healing. It is when these communications persist and form a true fistula that presents a risk for infection tracking into the synovial space. The patients discussed in the present article were at risk for acquiring suppurative tenosynovitis.

The optimal management of tenosynovial fistulae is unclear and lacks evidence. Conservative treatment with immobilization for up to two weeks has been reported to be effective with synovial fistulas of the knee (10). Immobilization and antibiotics for flexor tenosynovial fistulas of the palm were not shown to be effective in the literature, although the conclusion is limited due to a low level of evidence (9). Immobilization was used in case 1 for a period of two weeks and both 


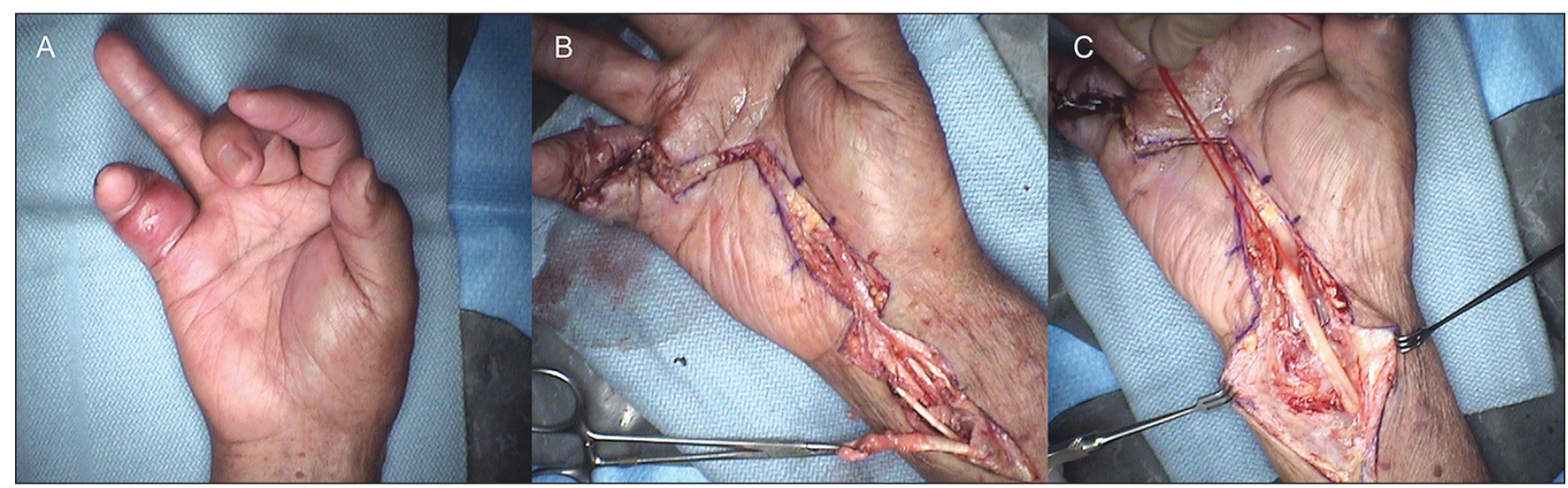

Figure 2) A. Case 2: Intraoperative photograph of the proximal phalangeal swelling of the right little finger. It had swollen further by the day of surgery and continued to spontaneously drain synovial fluid. B. The median nerve is identified and protected before excision of proliferative tenosynovium in the distal forearm. C. Proximal end of the flexor digitorum profundus of the ring finger is identified. Incision of the flexor sheath of the little finger drained synovial fluid

had received oral antibiotics. Drainage of synovial drainage persisted despite these measures. In contrast, definitive surgical excision did eliminate the synovial fistulas.

Patients with inflammatory arthritides, such as rheumatoid arthritis, may also be at higher risk for developing synovial fistulas $(15,16)$. Both case 1 and case 2 presented similarly with an acute painless swelling of a digit that may have represented a localized accumulation of synovial fluid from the underlying proliferative tenosynovitis. Other comorbid factors that impair wound healing, such as age and immunosuppression for rheumatoid arthritis or renal transplantation, likely contributed to the development of the tenosynovial fistulas.

\section{SUMMARY}

Although the literature is scarce, the development of tenosynovial fistula should be recognized as a possible complication of inflammatory flexor tenosynovitis. Patients with an underlying inflammatory process or comorbid factors that would impair wound healing should be identified as having a higher risk for developing this complication. Synovial fistulas themselves are benign but represent a possible site of infection into the synovial space. The definitive treatment of this problem is extensive flexor tendon tenosynovectomy, which may extend from the digit to the musculotendinous junction of the forearm and patients need to be forewarned of this.

DISCLOSURES: The authors have no financial disclosures or conflicts of interest to declare.

\section{REFERENCES}

1. Draeger RW, Bynum DK Jr. Flexor tendon sheath infections of the hand. J Am Acad Orthop Surg 2012;20:373-82.

2. Fulcher SM, Kiefhaber TR, Stern PJ. Upper-extremity tendinitis and overuse syndromes in the athlete. Clin Sports Med 1998;7:433-48.

3. Lebiedz-Odrobina D, Kay J. Rheumatic manifestations of diabetes mellitus. Rheum Dis Clin North Am 2010;36:681-99.

4. Ferlic DC. Rheumatoid flexor tenosynovitis and rupture. Hand Clin 1996;12:561-72.

5. Bullocks JM, Downey CR, Gibler DP, Netscher DT. Crystal deposition disease masquerading as proliferative tenosynovitis and its associated sequelae. Ann Plast Surg 2009;62:128-33.

6. Chim HW, Reese SK, Toomey SN, Moran SL. Update on the surgical treatment for rheumatoid arthritis of the wrist and hand. J Hand Ther 2014;27:134-42.

7. Wheen DJ, Tonkin MA, Green J, Bronkhorst M. Long-term results following digital flexor tenosynovitis in rheumatoid arthritis. J Hand Surg Am 1995;20:790-4.

8. Will R, Lubahn J. Complications of open trigger finger release. J Hand Surg Am 2010;35:594-6.

9. Naam NH. Flexor tenosynovial fistulas in the palm. J Hand Surg Am 2012;37:925-9.

10. Yiannakopoulos CK. Diagnosis and treatment of postarthroscopic synovial knee fistulae: A report of four cases and review of the literature. J Knee Surg 2007;20:34-8.

11. Allum R. Complications of arthroscopy of the knee. J Bone Joint Surg Br 2002;84:937-45.

12. Rasmussen S, Hjorth Jensen C. Arthroscopic treatment of impingement of the ankle reduces pain and enhances function. Scand J Med Sci Sports 2002;12:69-72.

13. Torres JA, Wright TW. Synovial cutaneous fistula of the shoulder after failed rotator cuff repair. Orthopedics 1999;22:1095-7.

14. Shirley DS, Mullet H, Stanley JK. Extensor tendon sheath fistula formation as a complication of wrist arthroscopy. Arthroscopy 2008;24:1311-2.

15. Bennett RM, Hughes GR, Bywaters EG, Holt PJ. Studies of a popliteal fistula. Ann Rheum Dis 1972;31:482-6.

16. Patiño Ruiz E, Tintue Eguren T, Jimenez Palop M, et al. Cutaneous fistula from a popliteal cyst in a female patient with rheumatoid arthritis. Rev Rhum Mal Osteoartic 1985;52:115-7. 